\title{
AS RELAÇÕES FAMILIARES E O NÍVEL DE SOBRECARGA DO CUIDADOR FAMLIAR
}

\author{
The family relationship and the burden level on family caregivers \\ Las relaciones familiares y el nivel de sobrecarga del cuidador familiar
}

\author{
Maria Fernanda Manoel ${ }^{1}$ \\ Maria das Neves Decesaro ${ }^{4}$
}

Elen Ferraz Teston²

Maria Angélica Pagliarini Waidman ${ }^{3}$

Sonia Silva Marcon ${ }^{5}$

\section{RESUMO}

Estudo descritivo, de abordagem qualitativa, realizado com o objetivo de conhecer o significado de ser cuidador e a relação com o nível de sobrecarga em cuidadores familiares de doentes crônicos. Os dados foram coletados em julho de 2011 por meio de entrevista semiestruturada e aplicação da Escala de Sobrecarga de Zarit. Os informantes foram 10 cuidadores de usuários de um Programa de Acompanhamento Domiciliar da cidade de Londrina-Paraná. 0 escore médio obtido com a aplicação da escala foi de 54,6 pontos, o que indica sobrecarga moderada. Da análise das falas emergiram quatro categorias, as quais permitem identificar que o significado de ser cuidador está relacionado com o tipo de relação familiar construída ao longo da vida e com o grau de sobrecarga que experimentam. Conclui-se a necessidade de se reconhecer que os cuidadores familiares precisam de orientações e, acima de tudo, de cuidados, com vistas a minimizar o estresse experienciado.

Palavras-chave: Família. Enfermagem. Doença crônica. Cuidadores.

\begin{abstract}
A descriptive study with qualitative approach, realized with the purpose of knowing the meaning of being a caregiver and its relation with the burden level inflicted on family caregivers of chronic patients. Data was collected in July 2011 , through semistructured interview using the Zarit Burden Interview Scale. The information was taken from 10 caregivers who were taking part on a Family Follow-up Program in Londrina - Paraná State. The average score was 54.6 indicating a moderate burden. Four categories emerged allowing to identify that the meaning of being a caregiver is related to the type of family relationship built along the life and with the level of burden that was experienced. It is concluded that there is a need to recognize that family caregivers need guidelines, and above all they need to be taken care of in order to minimize the stress they experience.
\end{abstract}

Keywords: Family. Nursing. Chronic Disease. Caregivers.

\section{Resumen}

Estudio descriptivo, de abordaje cualitativo, realizado con el objetivo de conocer el significado de ser cuidador y la relación con el nivel de sobrecarga en cuidadores familiares de enfermos crónicos. Los datos fueron recolectados en julio de 2011, a través de entrevista semiestructurada y aplicación de la Escala de Sobrecarga de Zarit. Los informantes fueron 10 cuidadores de usuarios de un Programa de Acompañamiento Domiciliario de la ciudad de Londrina, Paraná. El puntaje medio obtenido con la aplicación de la escala fue de 54,6 puntos, lo que indica sobrecarga moderada. Del análisis de las hablas emergieron cuatro categorías, que permiten identificar que el significado de ser cuidador está relacionado al tipo de vínculo familiar construido a lo largo de la vida y al grado de sobrecarga experimentado. Se concluye la necesidad de reconocerse que los cuidadores familiares necesitan de orientaciones y sobre todo, que sean cuidados, pretendiendo minimizar el estrés experimentado.

Palabras clave: Familia. Enfermería. Enfermedad Crônica. Cuidadores.

\footnotetext{
${ }^{1}$ Enfermeira do Programa de Acompanhamento do Paciente Crônico da UNIMED - Londrina. Mestranda em Enfermagem na Universidade Estadual de Maringá - UEM. Londrina- PR. Brasil. E-mail: mariafernanda.manoel@gmail.com² Enfermeira da Secretaria Municipal de Jandaia do Sul. Mestranda em Enfermagem na UEM. Membro do Núcleo de Estudos, Pesquisa, Assistência e Apoio à Família - NEPAAF. Maringá-PR. Brasil. Email: elen1208@hotmail.com; 'Enfermeira. Doutora em Filosofia da Enfermagem. Docente do Programa de Pós-graduação em Enfermagem da UEM. Maringá - PR. Brasil. E-mail: angelicawaidman@hotmail.com; ${ }^{4}$ Enfermeira. Doutora em Fundamentos da Enfermagem. Docente da graduação em Enfermagem da UEM. Maringá - PR. Brasil. E-mail: mndecesaro@uem.br; ${ }^{5}$ Enfermeira. Doutora em Filosofia da Enfermagem. Docente do Programa de Pós-graduação em Enfermagem da UEM. Coordenadora do NEPAAF. Maringá-PR. Brasil. Email: soniasilva.marcon@gmail.com
} 


\section{INTRODUÇÃO}

0 aumento da expectativa de vida, das transformações econômicas, políticas, sociais e culturais produzidas pela sociedade, ao longo do tempo, modificaram de maneira significativa o perfil de saúde-doença da população brasileira, colaborando, por um lado, com a diminuição progressiva das mortes por doenças infecto-contagiosas e, por outro, com a elevação da morbimortalidade por doenças crônicas não transmissíveis (DCNT) ${ }^{1}$ que englobam as cardiovasculares (hipertensão arterial e o diabetes melito), as respiratórias crônicas e as neoplasias².

Por se tratarem de enfermidades de longa duração, as doenças crônicas demandam cuidados, sendo que a intensa atuação de cuidadores, projetos terapêuticos adequados, acesso aos serviços e ações integradas podem auxiliar no tratamento do indivíduo doente 3 . Nessa perspectiva, o domicílio hoje constitui um espaço no qual os indivíduos com doenças crônicas podem manter a estabilidade de sua condição, desde que a família participe e forneça todo o suporte necessário, seja no cuidado do preparo de uma refeição, proporcionando uma atividade de lazer, ou auxiliando na rotina do uso de medicamentos e no acompanhamento de consultas para avaliação do estado de saúde. Por essa razão, cuidar de um doente em casa é uma experiência, além de cada vez mais frequente, também complexa ${ }^{4}$.

Contudo, o processo de conviver e cuidar de um familiar portador de doença crônica é uma tarefa árdua, e em alguns grupos seu diagnóstico é vivido como uma crise na família, 0 que pode acarretar para os cuidadores familiares (CF) uma sobrecarga que é potencialmente promotora de estresse, ansiedade, medo e sofrimento, evoluindo, por vezes, para um processo de rompimento do equilíbrio familiar ${ }^{5}$.

0 termo "sobrecarga do cuidador" tem sido muito utilizado na literatura científica para se referir aos problemas físicos, psicológicos ou emocionais, sociais e financeiros que podem ser vivenciados pelos familiares de pessoas doentes ou idosos ${ }^{6}$.

A sobrecarga "gera" sentimentos que podem influenciar diretamente na qualidade do cuidado prestado, isto porque um cuidador estressado e ansioso não consegue realizar o cuidado de forma integral e tranquila 5 . Além disso, pode levá-lo a uma série de consequências, físicas e emocionais/psicológicas, que geram as doenças psicossomáticas, a hipertensão arterial, entre outras.

Acredita-se que conhecer o que significa ser cuidador, para o familiar de pacientes crônicos, e o peso da sobrecarga vivida por ele, permite melhor compreensão das interações da família com a doença, possibilitando, dessa forma, uma atuação diferenciada por parte dos profissionais de saúde ${ }^{5}$.

Assim, o presente estudo teve por objetivo conhecer a acepção de ser cuidador e sua relação com o nível de sobrecarga experenciado pelo cuidador familiar de paciente com doença crônica.

\section{MÉTODO}

Estudo descritivo de abordagem qualitativa realizado com cuidadores familiares de indivíduos com DCNT, participantes de um Programa de Acompanhamento Domiciliar de uma instituição privada da cidade de Londrina - Paraná.

Esse programa existe desde 2009 e é desenvolvido por uma equipe multidisciplinar: uma psicóloga, uma nutricionista, uma assistente social, dois educadores físicos, seis enfermeiros, um analista administrativo, um coordenador administrativo e uma coordenadora médica. 0 Programa de Acompanhamento Domiciliar tem por objetivo assistir tanto 0 indivíduo com doença crônica como sua família e estimular o autocuidado por meio de atividades de educação em saúde. Seu propósito final é melhorar a qualidade de vida do doente crônico e reduzir os custos assistenciais.

São convidados a participar do programa indivíduos com dificuldades de controle da doença, ou que já apresentaram complicações devido a ela, os quais são identificados a partir de um levantamento operacional realizado mensalmente no serviço. Uma vez inscritos no programa, os pacientes são acompanhados individualmente em seu domicílio por um enfermeiro, que é o profissional responsável não só por identificar suas necessidades de saúde, mas também pela gestão do caso, o que inclui elaborar um plano assistencial e fazer os encaminhamentos necessários para a boa condução da assistência planejada.

0 critério para a escolha dessa instituição foi o fato de ela oferecer um serviço de assistência aos indivíduos com hipertensão arterial, diabetes melito e/ou doença pulmonar obstrutiva crônica, com diferentes níveis de dependência.

Após autorização (da direção do programa), realizouse um levantamento dos prontuários dos indivíduos participantes do Programa de Acompanhamento Domiciliar, para identificar aqueles que apresentavam dependência para cinco ou mais atividades de vida diária. À ocasião, encontravamse inscritos no programa 496 pacientes de ambos os sexos, com idade entre 15 e 97 anos e que apresentavam uma ou mais doenças crônicas. Foram excluídos 100 deles por não apresentarem registro sobre o grau de dependência; 349 por apresentarem dependência apenas para algumas atividades; 37 por outros motivos como óbito e cuidador não familiar. Dessa forma, os cuidadores familiares de 10 pacientes que apresentavam dependência para cinco ou mais atividades de vida diária foram incluídos no estudo.

Os 10 sujeitos da pesquisa foram inicialmente contatados por telefone e convidados a participar do estudo. Os dados foram coletados por meio de entrevistas semiestruturadas, previamente agendadas, realizadas nos domicílios, e gravadas após consentimento. Em seu desenvolvimento, foram utilizadas as seguintes questões norteadoras: 1. Conte-me como o Sr. começou a cuidar do "nome da pessoa doente". 2) Há quanto tempo tornou-se cuidador?; 
3) Fale sobre o que significa ser cuidador para o Sr.; 4) Fale sobre o que o Sr. sente ao cuidar de "nome da pessoa doente"; 5) Fale sobre a sua vida após se tornar cuidador. Posteriormente, as entrevistas foram transcritas e categorizadas, seguindo os preceitos da análise de conteúdo do tipo temática? .

Ademais, com o intuito de relacionar o significado de ser cuidador com o grau de sobrecarga, também foi utilizada a escala de Zarit Burden Interview, que avalia o impacto do cuidado nas esferas física, psicológica e social. Ela é composta de 22 questões, e as respostas são apresentadas em escala do tipo Likert, com pontuação que varia de $1-5^{8}$. Os resultados encontrados foram submetidos à análise descritiva.

0 desenvolvimento do estudo ocorreu em conformidade com a Resolução n¹ 196/96 do Conselho Nacional de Saúde, e seu projeto foi aprovado pelo Comitê Permanente de Ética em Pesquisa com seres Humanos (COPEP) da Universidade Estadual de Maringá (Parecer n 275|2011 de 27 de maio de 2011). Todos os participantes foram informados dos objetivos do estudo e participaram após o consentimento formalizado por meio da assinatura do Termo de Consentimento Livre e Esclarecido. Para diferenciação dos sujeitos e preservação do anonimato, foi utilizada a letra $\mathrm{C}$ para representar o cuidador, seguida de um número para diferenciá-los, acompanhado da idade de cada cuidador e do tempo em que este realiza o cuidado.

\section{RESULTADOS E DISCUSSÕES}

Os pacientes assistidos pelos familiares tinham idade média de 81,6 anos e apresentavam diagnósticos médicos de hipertensão arterial associada a diabetes melito (4), hipertensão arterial (4) e diabetes melito (2). Todos apresentavam dependência total em decorrência de complicações das doenças de base, o que, por si só, já deixa evidente a necessidade de grande disposição e solidariedade por parte dos cuidadores. Porém, isso não basta, é de suma importância que os cuidadores recebam apoio institucional para que possam esclarecer dúvidas e ter auxilio no enfrentamento das dificuldades vivenciadas durante a execução do cuidado9.

Os 10 cuidadores familiares em estudo eram, em sua maioria, do sexo feminino (9), ocupavam a posição de filha (6), esposa (3) e esposo (1) e tinham média de idade de 61,8 anos. Nove deles apresentavam algum problema de saúde, dentre eles hipertensão arterial (3), hipertensão arterial e diabetes melito (3), diabetes melito (1), artrite reumatoide (1) e depressão (1). A presença de doenças crônicas nos cuidadores familiares pode ser decorrente direta ou indiretamente da função desempenhada, uma vez que a presença de uma doença crônica está associada a múltiplos fatores que afetam não só a pessoa a ser cuidada, como também a saúde de seu respectivo cuidador $^{10}$.
A média do tempo que a pessoa assumiu o papel de cuidador foi de 5,5 anos, com um mínimo de dois anos e máximo de 27 anos. 0 escore máximo encontrado com a aplicação da escala de Zarit Burden Interview foi de 72 pontos e o mínimo, de 40 pontos. 0 escore médio encontrado com a aplicação da escala foi de 54,6 pontos, o que indica que, de uma forma geral, os cuidadores apresentam sobrecarga moderada. Contudo, ao serem avaliados individualmente, observa-se que quatro cuidadores apresentam sobrecarga intensa; quatro moderada; dois, ausência de sobrecarga.

Ao correlacionar o escore de sobrecarga com o tempo de cuidado exercido pelos respectivos cuidadores, não foi observada relação direta entre o tempo de cuidado e o nível de sobrecarga, uma vez que a pessoa que exerce a função de cuidadora há menos tempo (dois anos) apresentou o maior nível de sobrecarga; a cuidadora com maior tempo de cuidado apresentou sobrecarga moderada e as duas cuidadoras com ausência de sobrecarga apresentaram média de tempo de cuidado de 3,5 anos.

A análise das entrevistas permitiram identificar quatro categorias, as quais possibilitam uma melhor compreensão da relação, de um lado, entre o grau de sobrecarga e a função de cuidar de pessoa dependente de cuidados e, de outro, os fatores que interferem nessa relação. São elas: 1) A relação familiar influenciando na forma de exercer o cuidado; 2) A sobrecarga refletida na obrigação em ser cuidador; 3) 0 significado de "ser cuidador" relacionado ao nível de sobrecarga; e 4) Mudanças que ocorreram na vida do cuidador e nas relações familiares.

\section{A relação familiar influenciando na forma de exercer o cuidado}

As relações familiares, especificamente entre 0 indivíduo que cuida e o que é cuidado, sofrem variações dependendo do tipo de família, contexto social e cultural em que estão inseridas e também da força e valor das relações estabelecidas ao longo dos anos ${ }^{11}$.

Considerando essas diferenças, encontraram-se divergências na forma como duas cuidadoras percebem a função que exercem:

Eu não deixei de fazer nada. Eu inclusive, vou para o baile, vou dançar. [...] Quando eu casei com ele, eu tinha amor, mas depois que ele ficou doente eu ia abraçar ele, beijar ele, ele me xingava de nome muito feio, e ele era muito farrista e biscateiro de mais da conta. [...] Ele era namorador, bebia caipirinha, cerveja, até que deu um derrame nele. Passado uns 20 anos que ele tava de cama, eu comecei a sair pra dançar. Mas até hoje sofro muito com isso. Tenho medo que ele morre. Eu não aceito a morte de ninguém (C8, 72anos, cuidadora há 27 anos). 
A leitura superficial da fala de C8 pode, até, dar a impressão de que ela desenvolveu um viver melhor após o adoecimento do esposo, na medida em que afirma não ter deixado de "fazer nada" e de, inclusive, ter começado a sair para dançar. Percebe-se que o fato de ter absorvido a função não influenciou diretamente sua vida. Contudo, não se pode deixar de considerar que há 27 anos ela cuida do seu esposo. 0 tempo que ela cuida, portanto, é quase o mesmo que ela teve de convívio com o esposo antes da doença, tempo este que, segundo seu relembrar, não era tão bom, pois além de beber, 0 esposo era também um homem sem compromisso e mulherengo.

Em sua fala, a cuidadora expressa uma dualidade de sentimentos, pois hora vê o cuidado como manifestação de dó e hora como prova de amor. Essa dualidade, provavelmente, é influenciada pelo tempo de execução do cuidado e pela fragilidade da relação do casal antes da doença, que era marcada pela presença de conflitos. Assim, conclui-se que os conflitos familiares presentes, particularmente na relação conjugal, constituem uma fonte importante de estresse familiar ${ }^{12}$, possibilitando inferir que eles influenciam as relações parentais e, consequentemente, a forma de exercer o cuidado.

0 cuidado, nesse caso, aparece como uma função inerente ao casamento e evidencia que existe um componente afetivo que conduz essa atuação e contribui para o exercício do cuidado movido por um sentimento de carinho, de gostar do outro, como pode ser percebido na fala a seguir:

Deixei de fazer muita coisa. Nós vivia viajando pra Mato Grosso, pescar, participava de concurso de karaokê, que a gente gostava muito [...] (C6, 69anos, cuidadora há 2 anos).

C6 revela, em sua fala, o quanto ela e o esposo eram companheiros na realização das atividades antes da doença e que existia uma relação de cumplicidade entre eles. Nesse sentido, sua vida mudou muito, pois "perdeu" o parceiro para os momentos de lazer e prazer. Ademais, muitas pessoas passam a vida planejando o futuro para quando se aposentarem, ficarem idosos. Viagens, passeios, pescas, amigos, sonhos e ideais talvez nunca possam ser realizados, pois a doença crônica, muitas vezes, ceifa-os, trazendo tristezas e frustrações, além de algumas vezes torná-los cuidadores de seus companheiros. Um estudo realizado em Santa Catarina constatou que as cuidadoras familiares de idosos que tinham atitudes de solidariedade, gratidão e responsabilidade apresentavam uma relação estável com o indivíduo cuidado e que não existia conflito de papéis entre os dois, o que contribuía para uma melhor qualidade no cuidado prestado ${ }^{12}$

Observou-se que a cuidadora demonstrava muita dedicação e amor na realização dos cuidados que exercia para o marido já há dois anos, e apesar de ser hipertensa, sentia-se feliz com a multiplicidade de funções enquanto dona-de-casa, cozinheira e cuidadora. Contribui para isso, o bom relacionamento do casal antes da doença e a certeza de que, se fosse com ela, o marido cuidaria dela tão bem quanto ela cuida dele.

Evidenciou-se que, no início da doença, a família encontrava-se fragmentada quanto à divisão dos cuidados; porém, diante das dificuldades e necessidades do dia-a-dia, acabou por se organizar de forma integrada, e todos participam, em menor ou maior grau, desta atividade, e isso reflete as relações de causalidades. Portanto, as relações afetivas e pessoais desenvolvidas ao longo da vida podem determinar a qualidade das relações familiares diante da doença, ${ }^{13}$ pois, no cotidiano familiar, as relações se configuram de acordo com 0 ciclo de vida, e este é dinâmico, sendo o palco da existência individual e coletiva das pessoas que convivem perante determinada facticidade do viver em família.

\section{A sobrecarga refletida na obrigação em ser cuidador}

Entre os motivos que levaram os familiares a assumirem a função de cuidador, o mais frequente foi a ausência de outras pessoas que pudessem desenvolver essa tarefa. Cuidar, portanto, surgiu como uma obrigação, e não uma opção de vida.

[...] Com a minha mãe eu acho que ser cuidador é uma obrigação, porque ela cuidou tantos anos de mim, né [...] (C3, 59anos, cuidadora há 5 anos).

Só estava eu e minha mãe, né. Mas ela não tinha nada de doença. Quando ela parou de andar de repente, aí eu comecei a cuidar porque só tinha eu e ela. Fico feliz por cuidar de minha mãe, é difícil, mais fico feliz (C5, 57anos, cuidadora há dois anos).

Quando ela ficou doente e minha irmã já estava doente, eu vi que tinha que ser eu ou eu (C10, 54anos, cuidadora há 5 anos).

A carga emocional envolvida na relação familiar entre mãe e filho influencia diretamente nessa função que oscila entre obrigação e gratidão. 0 ser filho (a) determina a responsabilidade de assumir o cuidado. Durante a entrevista, os olhos do C3 transmitiam a tristeza e mágoa devido à forma como sua mãe a tratava. Ademais ela se ressentia por não poder ter vida própria e, inclusive, pelo fato de ter parado de trabalhar para cuidar da mãe. Contudo, embora não tenha mais vontade de cuidar de si, refere cuidar de sua mãe com todo carinho.

Estudo realizado com cuidadores de idosos doentes/ fragilizados, e que investigou os principais motivos que levaram a pessoa a se tornar cuidador, constatou que os mais citados foram a obrigação moral alicerçada em aspectos culturais e religiosos; a condição de conjugalidade, ou seja, o fato de ser esposo ou esposa; e a ausência de outras 


\section{Relações familiares e sobrecarga do cuidador}

Manoel MF, Teston EF, Waidman MAP, Decesaro MN, Marcon SS pessoas para a tarefa do cuidar, casos em que o cuidador assume essa incumbência não por opção, mas, por força das circunstâncias ${ }^{9}$. Cabe salientar que tornar-se cuidador, na maioria das vezes, não é planejado nem escolhido, e a maneira como evolui depende da característica da doença, das habilidades do cuidador e da posição deste dentro da família. Observou-se que C5, por exemplo, apesar de possuir necessidades especiais (comprometimento cognitivo), demonstrou, durante a entrevista, carinho e alegria por cuidar de sua mãe. Ela não sabe ler nem escrever e refere que cuidar é uma obrigação de filha, porém em momento algum demonstrou cansaço ou desanimo ao realizá-lo.

Os níveis de sobrecarga das cuidadoras 3, 5 e 10 foram respectivamente 66,40 e 53 pontos, índices estes que demonstram sobrecarga intensa para C3, ausência de sobrecarga para C5 e sobrecarga moderada para C10, o que pode estar relacionado com os diferentes significados atribuídos por elas ao fato de serem cuidadoras.

Em alguns casos, os membros da família se organizam de acordo com as necessidades de seus integrantes.

Eu cuido desde que minha mãe teve AVC, ela só tinha eu para cuidar porque meus irmãos não me ajudam e meu pai também é doente. Como eu preciso trabalhar a noite, porque tenho dois filhos para sustentar, consegui a ajuda do meu irmão que agora separou e das minhas outras irmãs que revezam entre elas duas para ficar com ela de noite. Mas durante o dia, de segunda a segunda, sou eu: banho, comida, tudo sou eu (C9, 54anos, cuidadora há 3 anos).

As relações familiares estabelecidas anteriormente à doença influenciam e determinam a distância familiar. Geralmente a forma de cuidar em família segue uma configuração anterior ao aparecimento da doença ou a disponibilidade de pessoas para cuidar. Ou seja, na vida familiar, existe uma hierarquia no que se refere ao compromisso em relação ao cuidado, assim é possível observar uma espécie de determinação velada de tarefas que devem ser desempenhadas, de acordo com as diferentes situações ${ }^{14}$. Por exemplo, a responsabilidade é sempre do filho mais velho, do filho que ainda está em casa, do filho que não trabalha, entre outras convenções, que seriam totalmente saudáveis se não significasse assumir essa função sozinho, sem apoio de outras pessoas.

No relato de C8, observou-se que, na ausência de compromisso dos filhos, ela assumiu sozinha a função de cuidar.

Comecei a cuidar dele quando ele teve AVC. Eu tenho dois filhos com ele, mas eles casaram, então sobrou eu pra cuidar dele. Então comecei a cuidar sozinha e tenho que me virar (C8, 72 anos, cuidadora há 27 anos).

Muitas vezes, o conjugue se percebe sozinho para exercer o cuidado, pois os filhos julgam ser dos pais a responsabilidade de cuidar um do outro, pelo compromisso da união matrimonial. Entretanto, nota-se que nem todas as pessoas possuíam uma relação familiar fortalecida pelo afeto, de forma que o cuidar foi revelado como uma obrigação, e, independentemente do grau de parentesco, essa função foi vista como uma designação que se estabeleceu ao longo da vida, conforme observado nos extratos de algumas falas: "é uma obrigação porque ela cuidou tantos anos de mim" (C3), "só tinha eu para cuidar" (C8), "comecei a cuidar sozinha" (C9) e "vi que tinha que ser eu ou eu" (C10).

Ao relacionarmos o grau de sobrecarga predominante, que foi o moderado, verificamos que a maneira como o cuidador enfrenta e assume a nova função influenciará diretamente no grau de sobrecarga apresentado.

Em algumas situações o cônjuge é o indivíduo mais próximo do doente e é quem assume o papel de cuidador. Essa decisão parece ocorrer devido às normas de solidariedade que são estabelecidas entre os membros de uma mesma geração, partindo do pressuposto que participaram de projetos pessoais e familiares comuns a ambos ${ }^{14}$.

\section{0 significado de "ser cuidador" relacionado ao nível de sobrecarga}

Quando questionados sobre o que é "ser cuidador" de uma pessoa dependente, ressaltaram, em sua maioria, que a responsabilidade é o fator que atribui significado a essa ação.

Sei lá. Muita responsabilidade né, porque ele está fazendo dieta pelo nariz agora [...](C2, 72anos, cuidadora há 2 anos).

[...] Ser cuidador é uma responsabilidade, porque assim você sempre tem que estar atenta, os remédios ela toma vários, então tem que estar sempre no horário, então ela é uma preocupação (C3, 59anos, cuidadora há 5 anos).

[...]Eu vejo o cuidado como uma responsabilidade (C7, 53anos, cuidadora há 3 anos).

Identificou-se nos depoimentos que a responsabilidade atribuída ao fato de ser cuidador é decorrente da complexidade dos cuidados que precisam ser realizados diariamente, o que envolve desde o número de medicamentos a serem administrados até a necessidade de oferecer alimentação por sonda. 
Outros cuidadores fizeram referência à preocupação e medo que envolve a sua atuação.

[...] tenho medo de acontecer alguma coisa. Faz dois anos que minha vida é medo, chegar em casa e ver ele ruim (C6, 69anos, cuidadora há 2 anos).

Um estudo realizado com o objetivo de traçar o perfil do cuidador familiar de idosos, no âmbito domiciliar, apontou que estes assumem a total responsabilidade pelo cuidado e com isso estão sempre sobrecarregados ${ }^{14}$. Esses dados confirmam os que foram encontrados neste estudo, visto que os cuidadores que percebem o cuidado com grande responsabilidade eram justamente aqueles que apresentam maior sobrecarga.

Acredita-se que o processo de cuidar poderia ser menos doloroso e angustiante caso fosse oferecido mais suporte ao cuidador, tanto por parte de outros integrantes da família como pelos profissionais de saúde. C6, por exemplo, apresentou 52 pontos na escala de sobrecarga, o que indica que está moderadamente sobrecarregada, indicando a necessidade de uma rede de apoio tanto na execução dos cuidados, como no esclarecimento de dúvidas.

Ao analisar os valores encontrados pela escala de Zarit ${ }^{8}$, observa-se que um escore de sobrecarga intensa (63 pontos) foi obtido por $\mathrm{C7}$, mas esta refere cuidar com muito amor e carinho, além de perceber essa dedicação como forma de crescimento.

Ah eu vique uma coisa que eu não tive antes; depois que eu trouxe ela pra cá para cuidar dela, eu vi que foi uma chance de pegar um amor muito grande por ela. Porque antes ela também trabalhava, era uma correria, então a gente não tinha essa liberdade, agora depois pra mim é gratificante, apesar de não ser fácil. É um crescimento pra gente $(C 7,53$, cuidadora há 3 anos).

Cabe salientar que $\mathrm{C} 5$, uma pessoa com necessidades especiais e que inclusive frequentou a Apae até os 14 anos, foi quem apresentou o menor escore de sobrecarga (40 pontos). Ela cuida de sua mãe há dois anos, e mesmo apresentando diagnóstico de hipertensão, diabetes e obesidade, exerce com dedicação a função de cuidadora. Isso permite inferir que cuidar, para ela, vai além de questões físicas, intelectuais e psicológicas, transcende o ser, é inerente a ela. Apesar de todas as questões individuais que poderiam limitar a oferta do cuidado, essa cuidadora tem em seu âmago a arte de cuidar.

Eu fico feliz, contente, porque é a única mãe que tem né, depois que morre acabou. Pra mim é fácil cuidar dela (C5, 57anos, cuidadora há 2 anos).
A análise dessa categoria evidenciou uma dualidade de sentimentos vivenciados pelos cuidadores e a forma como estes experienciam internamente e expressam o ato de cuidar. Nesse cenário, aponta que o profissional deve oferecer um aprendizado teórico/prático que forneça segurança ao cuidador inserido em um contexto baseado no respeito, na autonomia e na individualidade, visando ao reconhecimento e clareza do papel assumido.

Ultimamente é uma satisfação pra mim, embora seja muito desgastante. Mas eu, de certa forma, estou muito feliz [...] (C4, 61 anos, cuidadora há 3 anos).

C4, mesmo referindo ser desgastante exercer 0 cuidado, alcançou 44 pontos na escala de ZARIT(8), o que indica ausência de sobrecarga. Pode-se inferir que nem sempre uma situação que exige extrema dedicação e mudanças na vida diária do cuidador estará relacionada diretamente ao nível de sobrecarga.

Os cuidadores, quando questionados sobre os sentimentos experienciados a partir do momento em que assumiram o cuidado, revelaram possuir uma ambígua sensação de satisfação pelo dever cumprido e ao mesmo tempo percepção de desgaste pela quantidade de tarefas que necessita realizar ${ }^{15}$. Portanto, conclui-se que o significado de ser cuidador é influenciado por inúmeros sentimentos que permeiam o cuidar.

\section{Mudanças que ocorreram na vida do cuidador e nas relações familiares}

Entre as diversas mudanças que podem ocorrer na vida da pessoa que se torna cuidador, encontramos "alterações na dinâmica profissional".

Eu sempre gostei de mexer com oficina, tenho o maquinário, tenho tudo. Mas como vou assumir de fazer as coisas, e deixar ela aqui? (C1, 67anos, cuidador há 3 anos).

Constata-se que reconhecer-se como responsável pelo cuidado para com outra pessoa exige dedicação e transformações no modo de vida do cuidador. Assim, atividades corriqueiras e necessárias, inclusive para a sobrevivência, ficam comprometidas. Nesse sentido, a nova situação vivenciada exige dedicação total por parte daquele que assume a integralidade dos cuidados. E cuidar de uma pessoa dependente faz com que o estilo de vida do cuidador seja modificado em função das necessidades do outro. Independente do fato de aquele que cuida ser uma pessoa jovem ou idosa, suas atividades de lazer e convívio social acabam sendo alteradas ou anuladas, dando a ele a sensação de não ter autonomia para gerenciar a própria vida e ter de viver em função do outro ${ }^{16}$. 
Deixei meu filho e meu neto lá em São Paulo, e só tenho como ir pra lá de vez em quando. Tive que sair de lá, junto da minha família e vir pra cá. Não tenho amigos aqui, fico solitária (C4, 61anos, cuidadora há 3 anos).

A interpretação imediata da fala remete à percepção da transformação da vida da cuidadora e da abdicação de sua própria casa para cuidar da mãe, revelando que a cuidadora se refere à mãe sem lembrar que ela constitui sua família de origem.

Existe uma dinâmica no processo de cuidar que é uma relação tensionada, na qual os sujeitos envolvidos constroem seus espaços respectivos, dentro dos limites dessa nova relação pessoal. Desse modo, os cuidadores apontam que perdem a liberdade até mesmo em relação aos outros familiares, ou seja, quanto mais o doente necessita de cuidados ou se sente sozinho, mais o cuidador tende a ficar "isolado" no domicilio para cuidar deste e, consequentemente, mais distante fica de seus outros familiares e do contexto social, alterando as oportunidades de lazer e os hábitos diários.

\section{CONSIDERACÕES FINAIS}

Os resultados do estudo apontam que o significado de ser cuidador está diretamente associado ao tipo de relação familiar estabelecido ao longo da vida, aos sentimentos que afloram dessa relação, mas não necessariamente ao grau de sobrecarga experenciado pelo cuidador. Tal quadro indica, aos profissionais, a necessidade de investirem na formação de vínculos familiares, através do diálogo, levantamento de problemas e possíveis soluções com o intuito de fortificar esses laços e tornar o cuidador um aliado do doente. Além disso, os cuidadores necessitam sentir-se apoiados, valorizados e reconhecidos pelo trabalho que executam. Assim, o cuidado prestado poderá ser vivenciado não como algo esgotante, mas como um ato de afeto, ajudando o cuidador a não se sentir sobrecarregado.

A compreensão das interações da família com a doença permite ao profissional de enfermagem perceber que os cuidadores familiares também precisam de cuidados, de orientações e de estratégias para alívio do estresse. Desse modo, poderão ter melhores condições de vida e, consequentemente, poderão propiciar um cuidado com mais qualidade ao familiar doente.

Ademais, é necessário que se realizem investigações, visando à ampliação do conhecimento sobre os eventos que compõem o cuidado e sobre as relações familiares, a partir das experiências dos sujeitos.

Apesar das limitações e das perdas, o estudo buscou registrar a relevância dessa temática para a enfermagem, por se tratar de uma profissão que tem, em sua essência, o cuidado ao explorar as questões subjacentes ao processo de cuidar do familiar e as relações familiares envolvidas. Também não tem a intenção de esgotar o assunto, mas sim, instigar novas produções científicas e aprofundar as discussões sobre essa temática que visem reverter, positivamente, para a assistência em saúde.

\section{REFERÊNCIAS}

1 Ministério da Saúde (Brasil). Diretrizes e recomendações para o cuidado integral de doenças crônicas não transmissíveis. Brasilia(DF): Editora MS; 2008 (Série Pactos Pela Saúde, 8)

2 World Health Organization - WHO. Chronic disease. [serial on the Internet]; 2005 [citado em 2011 mar. 4]. Diponível em: <http://www.who.int/ topics/chroni c_dise ases>.

3 Malta DC, Merhy EE. 0 percurso da linha do cuidado sob a perspectiva das doenças crônicas não transmissíveis. Interface comun. saúde educ. 2010 Jul./Set.; 14(34): 593-605

4 Saraiva KRO, Santos ZMSA, Landim FLP, Lima HP,Sena, LV. 0 processo de viver do familiar cuidador na adesão do usuário hipertenso ao tratamento. Texto \& contexto enferm.

2007 jan./mar.; 16(1): 63-70.

5 Fernandes JJBR. A sobrecarga do cuidador familiar. [dissertação]. Lisboa(POR): Faculdade de Medicina de Lisboa (POR); 2009.

6 Veras RP, Caldas CP, Dantas SB, Sancho LG, Sicsú B, Motta LB et al . Avaliação dos gastos com o cuidado do idoso com demência. Rev. psiquiatr. clín. (São Paulo). 2007 Jan./Fev.; 34(1): 5-12.

7 Bardim L. Análise de Conteúdo. Lisboa: Ediç̃̃es 70; 2008.

8 Sequeira CAC. Adaptação e validação da escala de sobrecarga do cuidador de ZARTI. Revista referência. 2010 mar.; 12(2): 9-16.

9 Gonçalves LHT, Alvarez AM, Sena ELS, Santana LWS, Vicente FR. Perfil da família cuidadora de idoso doente/fragilizado do contexto sociocultural de Florianópolis, SC. Texto \& contexto enferm. 2006 out./dez; 15(4): 570-7.

10 Fernandes JJBR. A sobrecarga do cuidador familiar.[dissertação]. Lisboa (POR): Universidade de Lisboa; 2009.

11 Michelli MMM. Violência familiar: mitos e verdades Dissertação [dissertação]. São Paulo(SP): Faculdade de História, Direito e Serviço Social UNESP; 2009.

12 Souza WGA, Pacheco WNS, Martins JJ, Barra DCC, Nascimento ERP. Educação em saúde para leigos no cuidado ao idoso no contexto domiciliar. ACM arq. catarin. med. 2006 out./dez; 35(4): 56-63.

13 André SMFS, Cunha M, Rodrigues VMCP. Família enquanto entidade cuidadora. Millenium. 2010 dez; 39: 131-34.

14 Braz E, Ciosak SI. 0 tornar-se cuidadora na senescência. Esc. Anna Nery Rev. Enferm. 2009 abr.jun; 13 (2): 372-7. 
15 Pimenta GMF, Costa MASMC, Gonçalves LHT, Alvarez AM. Perfil do familiar cuidador de idoso fragilizado em convívio domestico da grande Região do Porto, Portugal. Rev. Esc. Enferm. USP. 2009 jul./set.; 43(3): 609-14

16 Barros JDS, Oliveira NJM, Silva SLB, Silva RS, Silva MFP. Percepção e expectativas de cuidadores no processo saúde/doença na pessoa idosa. Rev saúde. 2010 abr.jun; 4(2): 28-36. 